\title{
PEMBELAJARAN KOLABORATIF BERBASIS ONLINE
}

\author{
Novi Sofia Fitriasari ${ }^{1}$, Muhamad Renaldi Apriansyah ${ }^{2}$, Risma Nur Antika ${ }^{3}$ \\ Program Studi Sistem Informasi Kelautan, Universitas Pendidikan Indonesia \\ Email : novisofia@upi.edu ${ }^{1}$, muhamadrenaldia@upi.edu ${ }^{2}$, reeantalter@gmail.com ${ }^{3}$
}

\begin{abstract}
ABSTRAK
Pembelajaran kolaboratif adalah pembelajaran yang dilakukan oleh dua orang atau lebih untuk belajar secara bersama-sama. Salah satu tujuan pembelajaran kolaboratif adalah memberikan kesempatan kepada siswa untuk berpartisipasi secara aktif dalam proses pembelajaran atau yang dikenal dengan istilah student center. Permasalahan yang ada pada masa apademi Covid-19 mengakibatkan pembelajaran kolaboratif sulit dilakukan karena adanya social distancing, yang mengharuskan pembelajaran dilakukan dari rumah. Salah satu solusi yang diusulkan oleh penelitian ini adalah penggunaan teknologi berbasis internet untuk melakukan pembelajaran kolaboratif secara online. Aplikasi kolaboratif online yang dibahas pada penelitian ini adalah MOOCs APTIKOM, Google Classroom dan Aplikasi Sistem Manajemen Pengetahuan. Partisipan atau student yang memanfaatkan course di MOOCs tersebut masih dibawah 100 dan MOOCs APTIKOM memberikan layanan materi bidang informatika dan komputer yang dapat diakses secara bebas. Aplikasi google classroom yang merupakan aplikasi Web 2.0 dan aplikasi sistem manajemen pengetahuan(Asmape) dapat dimanfaatkan untuk pembelajaran kolaboratif secara online hal ini dibuktikan dengan telah diimplementasikannya google classroom pada mata kuliah evaluasi pembelajaran dan aplikasi Asmape telah dimanfaatkan pada mata kuliah basis data terutama untuk tugas kelompok membuat artikel ilmiah.
\end{abstract}

Kata Kunci: Asmape, Google Classroom, MOOCs, Pembelajaran Kolaboratif.

\section{ABSTRACT}

Collaborative learning is a process carried out by two or more people to learn together. One of the puposes of collaborative learning is to provide opportunities for students to actively participate in the learning process or known as the student-centered learning. The existing problems during the Covid-19 pandemic time made collaborative learning difficult to be implemented due to social distancing, which required learning from home. One of the solutions proposed by this study is the use of internet-based technology to conduct online collaborative learning. The online collaborative learning applications discussed in this study were APTIKOM's MOOCs, Google Classroom and Aplikasi Sistem Manajemen Pengetahuan (ASMAPE). The participants or students who utilized the courses at those MOOCs were still under 100 users and APTIKOM MOOCs provided a freely accessed service of informatics and computer materials. The Google classroom application, which is a Web 2.0 application, and Aplikasi Sistem Manajemen Pengetahuan (ASMAPE) can be used for online collaborative learning. This is proven by the implementation of Google classroom in Learning Evaluation course and the the use of ASMAPE application in Database course, especially for group assignments of scientific articles writing

Keywords: Asmape, Collaborative Learning, Google Classroom, MOOCs. 


\section{PENDAHULUAN}

Kondisi apademi covid 19 saat ini mengharuskan untuk social distancing, hal ini berdampak pada proses pembelajaran di Instansi pendidikan, dimana proses pembelajaran harus dilakukan dari rumah. Model pembelajaran kolaboratif, yang merupakan pembelajaran yang dilakukan oleh dua orang atau lebih untuk belajar secara bersama-sama, tentunya akan sulit dilakukan. Oleh karena itu dibutuhkan strategi pembelajaran inovatif yang memanfaatkan kemajuan teknologi dan komunikasi.

Strategi pembelajaran kolaboratif yang dibahas pada penelitian ini adalah pembelajaran kolaboratif yang memanfaatkan teknologi internet. Banyak penelitian yang membahas mengenai hal tersebut. Diantaranya dapat dilihat dari tiga penelitian sebagai berikut. Penelitian pertama membahas mengenai teknologi pembelajaran kolaboratif yang dapat dimanfaatkan oleh partisipan dalam jumlah yang banyak. Penggunaan Massive Open Online Courses (MOOCs) merupakan salah satu solusi yang ditawarkan (Manathunga \& Hernández-Leo, 2015), Penelitian kedua memanfaatkan online learning management system (LMS) di dalam proses pembelajarannya (Nurakun Kyzy et al., 2018), Penelitian ketiga membahas mengenai pengintergrasian Aplikasi Web 2.0 dengan LMS yang dapat membuat aplikasi LMS menjadi lebih interaktif (Chunyan et al., 2014). Pada penelitian ini mengkaji lebih lanjut.

1. Pembelajaran kolaboratif MOOCs Aptikom
2. Penerapan

pembelajaran kolaboratif berbasis online dengan menggunakan google classroom.

3. Penerapan pembelajaran kolaboratif berbasis online dengan menggunakan aplikasi sistem manajemen pengetahuan.

4. Kelebihan dan kekurangan pembelajaran kolaboratif berbasis online

\section{LANDASAN TEORI}

Pembelajaran kolaboratif yang dimaksud dalam penelitian ini adalah pembelajaran kolaboratif dengan bantuan komputer atau yang dikenal dengan istilah Computer-supported collaborative learning(CSCL). Pembelajaran kolaboratif dapat dilakukan secara synchronous (komunikasi secara langsung) dan atau asynchronous (komunikasi secara tidak langsung). Pembelajaran kolaboratif akan berhasil jika setiap individu didalam kelompok tersebut meyakini bahwa karya atau produk yang dihasilkan di dalam pembelajaran berkelompok akan lebih baik daripada dikerjakan secara individu (Laal, 2013). Salah satu keuntungan dari pembelajaran kolaboratif adalah dapat melatih siswa untuk sharing pengetahuan yang dimilikinya dan melatih siswa bekerja secara team work.

Teknologi pembelajaran kolaboratif online diantaranya MOOCs. LMS dan Aplikasi Web 2.0. Ciri dari MOOCs adalah massive, Open, online dan courses(Setyowati, 2015). Massive artinya skala partisipan yang mengikuti 
pembelajaran tidak terbatas. Open artinya setiap orang dapat mengikuti. Dilihat dari segi biaya ada beberapa MOOCs yang tanpa biaya, ada yang bayar untuk sertifikat dan ada beberapa yang bayar. online artinya semua aktivitas pembelajaran dilakukan secara online, namun dalam perkembangannya ada beberapa universitas yang menggunakan MOOCs sebagai bagian dari pembelajaran konvensional. Courses artinya Pembelajaran dilakukan secara lengkap sehingga kompetensi peserta yang diidentifikasikan diawal tercapai. Aktivitas pembelajaran mulai dari menyimak paparan materi, membaca bahan bacaan, melakukan diskusi secara online, mengerjakan tugas, kuis dan mendapatkan sertifikat jika sudah menyelesaikan pembelajaran.

LMS adalah aplikasi berbasis website yang digunakan untuk mendukung proses pembelajaran. Aplikasi Sistem Manajemen

Pengetahuan(http://asmape.com)

merupakan aplikasi yang menerapkan konsep LMS Tampilan awal dari aplikasi tersebut dapat dilihat pada gambar 1 .
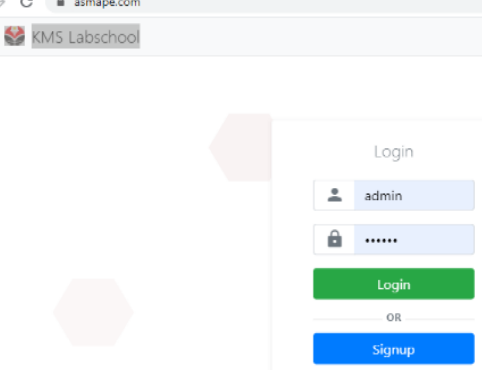

Gambar 1. Tampilan awal aplikasi asmape diakses tanggal 18 Agustus 2020

Aplikasi ini memiliki empat layanan yang terdiri dari Publication, Collaboration, E-Learning dan Discovery.
Layanan tersebut dapat dilihat pada gambar 2

Publication layanan ini dapat digunakan oleh user untuk membantu di dalam membuat karya tulis secara bersama-sama pada layanan ini memanfaatkan document collaboration tools seperti google drive. Collaboration layanan ini dapat digunakan untuk diskusi secara online. $E$ Learning dapat digunakan untuk sharing dokumen maupun video dan juga terdapat online kuis. Discovery dapat digunakan untuk pencarian dan pengambilan pengetahuan yang sudah ada dalam bentuk dokumen ataupun video.

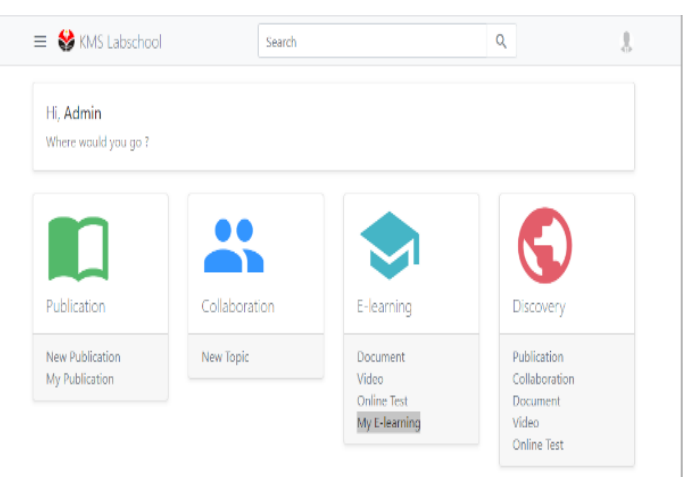

Gambar 2. Tampilan layanan aplikasi Sistem Manajemen Pengetahuan diakses tanggal 18 Agustus 2020

Aplikasi Web 2.0 dapat dikatakan sebagai aplikasi website yang memiliki user interface yang interaktif dan dapat mendukung adanya layanan kolaboratif. Contoh aplikasi Web 2.0 diantaranya adalah Wiki, Blogs, social networking, google doc, google drive dan google classroom. Pada sub bab ini akan membahas lebih lanjut mengenai google classroom yang dapat menggantikan pembelajaran di kelas. 
Google classroom dapat dikatakan sebagai kelas virtual yang memungkinkan partisipan untuk berkomunikasi dengan partisipan yang lain, atau pun dengan pengajar, mengakses materi berupa dokumen ataupun video, dan juga digunakan untuk mengerjakan atau mengirimkan tugas. Berdasarkan penelitian yang dilakukan oleh Iftakhar sebagian besar partisipan menyatakan bahwa Google Classroom efektif untuk pembelajaran dan mudah untuk digunakan(Iftakhar Shampa, 2016).

Google classroom dirancang dengan mengintegrasikan aplikasi google yang lain seperti google drive, google docs, google sheets, google slides dan google calendars. Google classroom juga bisa diakses secara mobile. Selain teknologi berbasis web, media mobile dapat dimanfaatkan untuk pembelajaran kolaboratif. Pemanfaatan media mobile dapat mendukung siswa untuk belajar secara kolaboratif dengan rekannya dan dapat menumbuhkan motivasi belajar lebih besar dari pada lingkungan belajar lainnya (Ryu \& Parsons, 2012)

\section{METODE PENELITIAN}

Tahapan penelitian dapat dilihat pada gambar 3. Tahap awal dilakukan kajian MOOCs Aptikom dengan cara melakukan studi literatur mengenai MOOCs dan mengkaji website MOOCs Aptikom pada alamat https://mooc.aptikom.or.id/. Langkah berikutnya mengimplementasikan google classroom dan asmape pada mata kuliah terutama untuk kegiatan pembelajaran kolaboratif dan tahap terakhir mengkaji kelebihan dan kekurangan aplikasi kolaboratif pembelajaran online berdasarkan kajian yang sudah dilakukan sebelumnya.

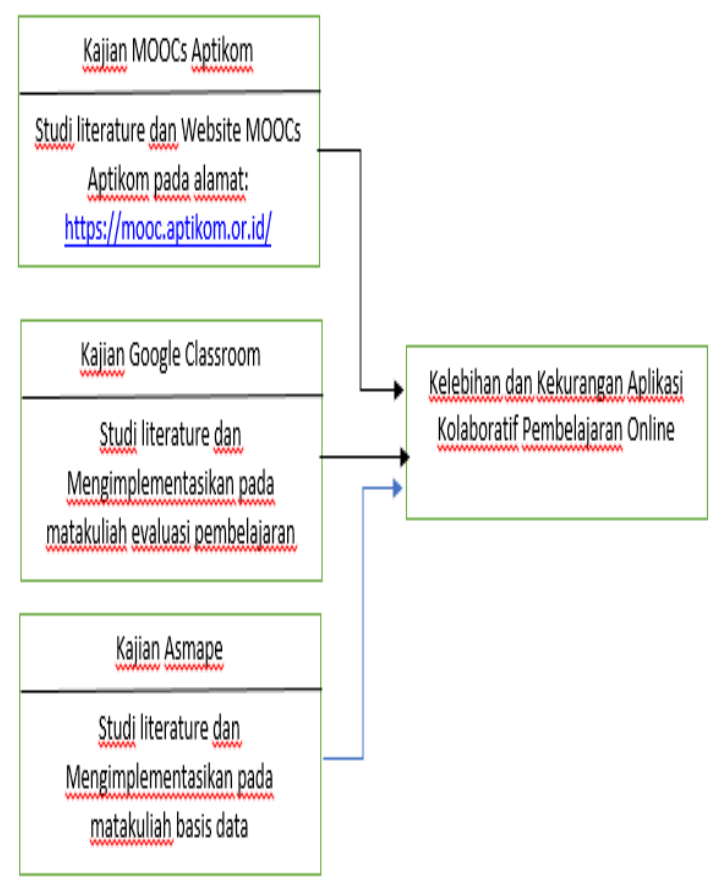

Gambar 3. Tahapan Penelitian

\section{HASIL DAN PEMBAHASAN}

Pada sub bab ini mengkaji empat bahasan utama yaitu teknologi pembelajaran MOOCs APTIKOM, penerapan google classroom, penerapan aplikasi sistem manajemen pengetahuan dan mengkaji mengenai Kelebihan dan kekurangan pembelajaran kolaboratif berbasis online

4.1. Pembelajaran Kolaboratif Massive Open Online Course (MOOCs) APTIKOM.

Platform MOOCs yang dimiliki oleh APTIKOM(Asosiasi Pendidikan Tinggi Informatika dan Komputer) dapat dilihat pada gambar 4. MOOCs APTIKOM memberikan empat layanan yaitu open content, open courseware, open education dan certified open courseware. 


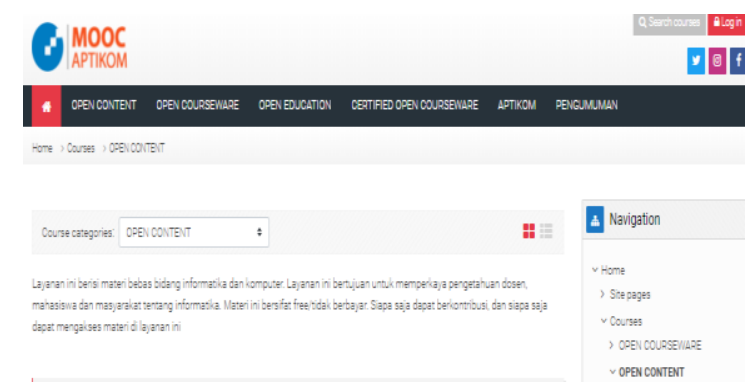

Gambar 4. Tampilan open course Moocs APTIKOM

(https://mooc.aptikom.or.id/course/index.p

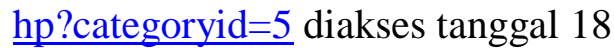

Agustus 2020)

Partisipan di dalam pembelajaran kolaboratif berbasis online dapat dilakukan dalam jumlah besar (Manathunga \& Hernández-Leo, 2015) ataupun dalam kelompok kecil dimana anggotanya tidak lebih dari enam partisipan (Robinson et al., 2017). Minat terhadap teknologi pendidikan dalam jumlah peserta yang besar semakin meningkat sejalan dengan berkembangnya Massive Open Online Courses (MOOCs)(Sonwalkar et al., 2013). MOOCs dapat dikatakan sebagai media pembelajaran online yang memanfaatkan kecanggihan teknologi sehingga dapat mendukung jumlah partisipan yang besar (Setyowati, 2015).

Jumlah partisipan berdasarkan hasil literature review paper dari Manatungha dapat dilihat pada tabel 1 bawah ini.

Tabel 1. Jumlah Partisipan MOOCs (Manathunga \& Hernández-Leo, 2015)

\begin{tabular}{ll}
\hline Presentase & Jumlah Partisipan \\
\hline 55 & Kurang dari 100 \\
37 & 100 sampai dengan \\
& 1000 \\
8 & Lebih dari 1000 \\
\hline
\end{tabular}

Jumlah partisipan pada MOOCs Aptikom yang diakses pada tanggal 18
Agustus 2020 masih kurang dari 100. Partisipan MOOCs Aptikom adalah mahasiswa dari perguruan tinggi yang telah bekerja sama dengan APTIKOM. Tabel 2 memperlihatkan contoh jumlah partisipan dari course yang dibuka.

Tabel 2. Jumlah Partisipan MOOCs APTIKOM

\begin{tabular}{ll}
\hline Course & $\begin{array}{l}\text { Jumlah } \\
\text { Partisipan }\end{array}$ \\
\hline $\begin{array}{l}\text { Pengantar } \\
\text { Metodelogi }\end{array}$ & 26 students \\
$\begin{array}{l}\text { Penelitian } \\
\text { Cloud Computing }\end{array}$ & 14 students \\
Jaringan Saraf & 14 students \\
Tiruan & \\
Penulisan Ilmiah & 29 students \\
E-Bisnis & 23 students \\
Cyber Computer & 25 students \\
Security & \\
\hline
\end{tabular}

Tabel 3 memperlihatkan platform Moocs dari aspek profit, akses, sertifikat dan institusional credits.

Tabel 3. Perbedaan Platform MOOCs (Yuan et al., 2013)

\begin{tabular}{|c|c|c|c|c|}
\hline $\begin{array}{l}\text { Initiati } \\
\text { ves }\end{array}$ & $\begin{array}{l}\text { pro } \\
\text { fit }\end{array}$ & $\begin{array}{l}\text { Free } \\
\text { to } \\
\text { Acc } \\
\text { ess }\end{array}$ & $\begin{array}{l}\text { Certific } \\
\text { ation fee }\end{array}$ & $\begin{array}{l}\text { institusi } \\
\text { onal } \\
\text { credits }\end{array}$ \\
\hline eDX & $x$ & $\sqrt{ }$ & $\sqrt{ }$ & $\sqrt{ }$ \\
\hline $\begin{array}{l}\text { Course } \\
\text { ra }\end{array}$ & $\sqrt{ }$ & $\sqrt{ }$ & $\sqrt{ }$ & $x \sqrt{ }$ \\
\hline Udacit & $\sqrt{ }$ & $\sqrt{ }$ & $\sqrt{ }$ & $x \sqrt{ }$ \\
\hline $\begin{array}{l}\text { y } \\
\text { Udemy }\end{array}$ & $\sqrt{ }$ & $x \sqrt{ }$ & $\sqrt{ }$ & $x \sqrt{ }$ \\
\hline $\mathrm{P} 2 \mathrm{PU}$ & $X$ & $\sqrt{ }$ & $X$ & $\sqrt{ }$ \\
\hline \multicolumn{5}{|c|}{ Keterangan } \\
\hline $\begin{array}{l}x \quad \text { Not } \\
\sqrt{ } \text { Featu } \\
x \sqrt{ } \text { Featu }\end{array}$ & $\begin{array}{l}\text { Feat } \\
\text { re } \mathrm{Pr} \\
\text { re } \mathrm{Pa}\end{array}$ & $\begin{array}{l}\text { re } \\
\text { sent } \\
\text { tially } P\end{array}$ & esent & \\
\hline
\end{tabular}


MOOCs Aptikom memiliki layanan free/tidak berbayar siapa saja dapat berkontribusi dan mengakses materi bidang informatika dan komputer. Layanan pembelajaran tersebut mengikuti Standar Nasional Pendidikan Tinggi yang terdiri dari 16 pertemuan termasuk UTS dan UAS. Materi yang diberikan sudah dilakukan proses pengkajian oleh komisi penjaminan mutu. Proses pembelajaran yang dilakukan akan menghasilkan nilai yang dapat digunakan mahasiswa sebagai pemenuhan sebagian mata kuliah di perguruan tingginya. Hal ini tentunya dapat mendukung program pemerintah "Kampus Merdeka dan Merdeka Belajar"

\subsection{Penerapan Google classroom}

Pada paragraf berikutnya akan diperlihatkan contoh tampilan dari google classroom. Gambar 5 merupakan tampilan kelas virtual untuk mata kuliah evaluasi pembelajaran

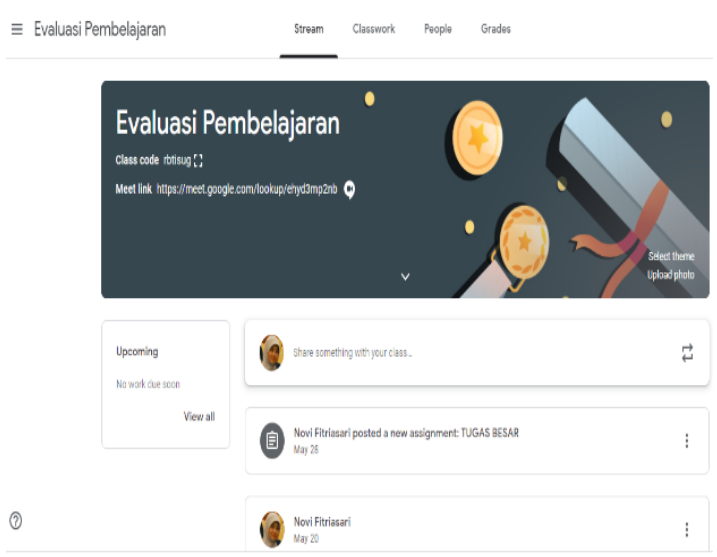

Gambar 5. User Interface google classroom : Stream

Terdapat empat content pada google classroom yaitu stream classwork, people dan grade. User interface stream dapat dilihat pada gambar 5. Stream dapat digunakan untuk sharing file dokumen, atau video dan juga dapat digunakan untuk med forum. Classwork dapat digunakan untuk memberikan tugas dan dapat menjadwalkan kapan tugas tersebut harus dikumpulkan. User interface classwork dapat dilihat pada gambar 5 .

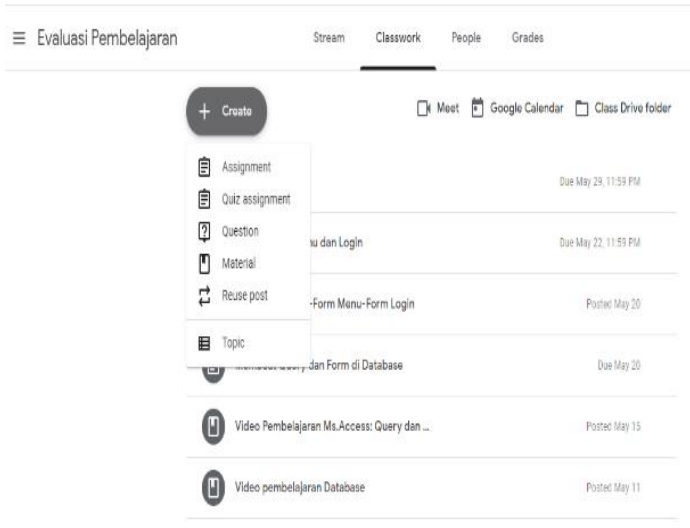

Gambar 5. User Interface google classroom : Classwork

People. Pada user interface people dapat melihat partisipan yang mengikuti mata kuliah evaluasi pembelajaran. Kelebihan dari google classroom ini mata kuliah dapat dilakukan secara team teaching yaitu proses pembelajaran dilakukan oleh dua atau lebih dosen. User Interface people dapat dilihat pada gambar 6.

$\equiv$ Evaluasi Pembelajaran

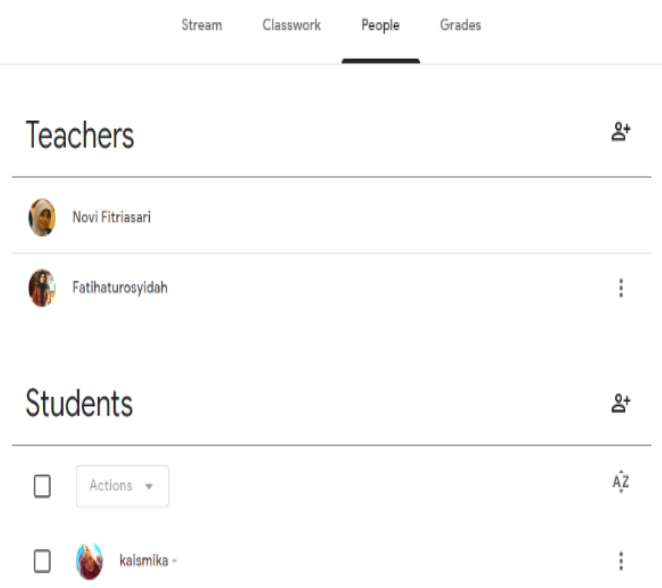

Gambar 6. User Interface google classroom: People 
Grades. User interface grades digunakan untuk menilai tugas yang sudah diberikan sebelumnya. Seperti terlihat pada gambar 7

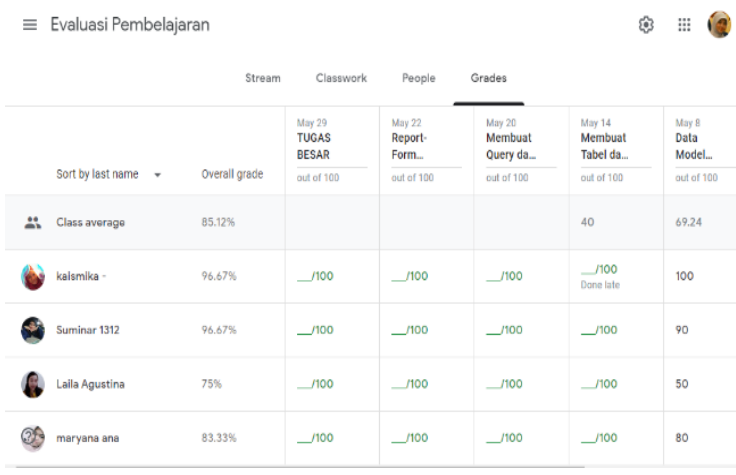

Gambar 7. User Interface google classroom : Grades

\subsection{Penerapan Aplikasi Asmape.com}

Penerapan teknologi pembelajaran kolaboratif di Program Studi Sistem Informasi Kelautan Kampus UPI di Serang pada mata kuliah Basis Data. Teknologi yang digunakan adalah dengan menggunakan Aplikasi Sistem Manajemen Pengetahuan yang memiliki konsep sama dengan LMS.

Kelebihan dari aplikasi ini adalah terdapat menu untuk membuat group/kelompok. Sebagai contoh gambar 8 dibawah ini akan diperlihatkan user interface group dengan anggota kelompoknya.

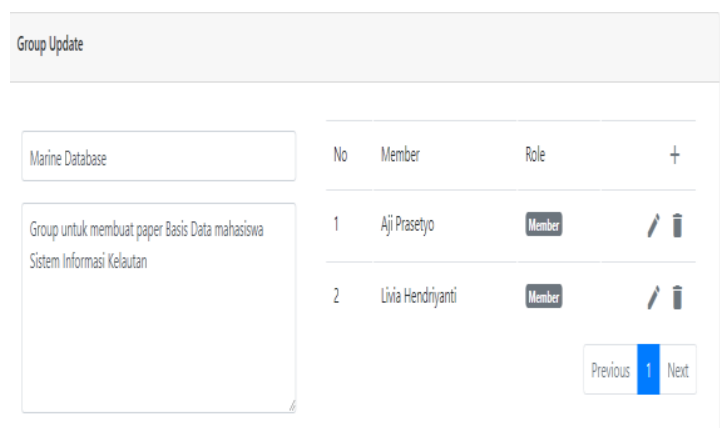

Gambar 8. User Interface nama group

Marine Database dan anggota kelompoknya.
Salah satu contoh tugas yang diberikan dalam mata kuliah database adalah membuat paper secara bersamasama dengan menggunakan layanan publication yang terdapat di aplikasi Sistem Manajemen Pengetahuan. Layanan ini diintergrasikan dengan aplikasi Web 2.0 yaitu google.drive, sehingga dapat meningkatkan kolaborasi antar partisipan di dalam Collaborative writing. Gambar 9 merupakan contoh user interfacenya

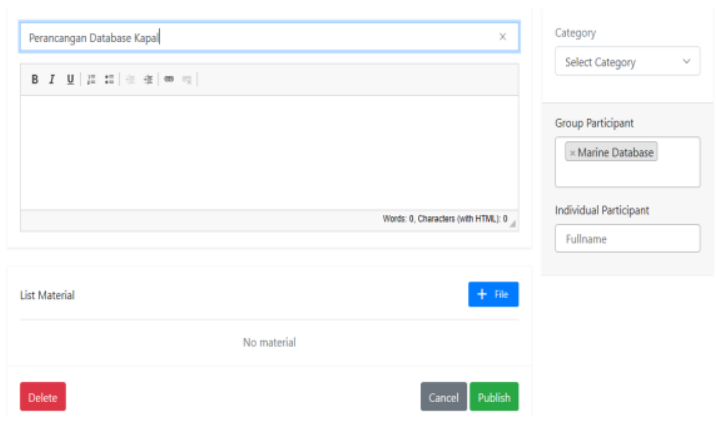

Gambar 9. User Interface untuk mengusulkan Judul Paper dan group/individual partisipannya.

Setelah semua field pada gambar 9 diisi dan kemudian klik publish maka akan tampil user interface pada gambar 10 .

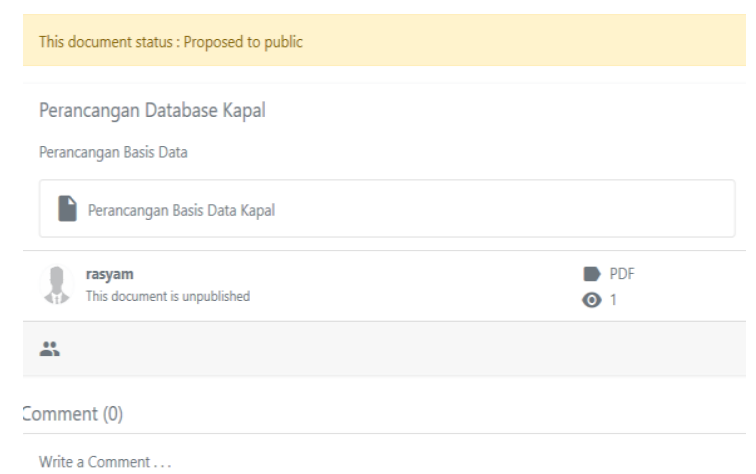

Gambar 10. User Interface untuk memohon publish paper ke admin

Approval publish paper akan dilakukan oleh admin, pada tahap inilah terdapat integrasi dengan Google Drive untuk menyimpan file paper tersebut yang 
kemudian nanti bisa diedit dengan bantuan google.doc. Gambar 11 merupakan user interface untuk admin melakukan approval dengan empat langkah yang dilakukan yaitu

a. Download file satu per Satu

b. Upload file dokumen ke collaboration tools seperti google drive, sebelumnya buat folder terlebih dahulu

c. Kemudian insert link yang didapat dari collaboration tools seperti pada gambar 12

d. Setelah itu baru klik approve

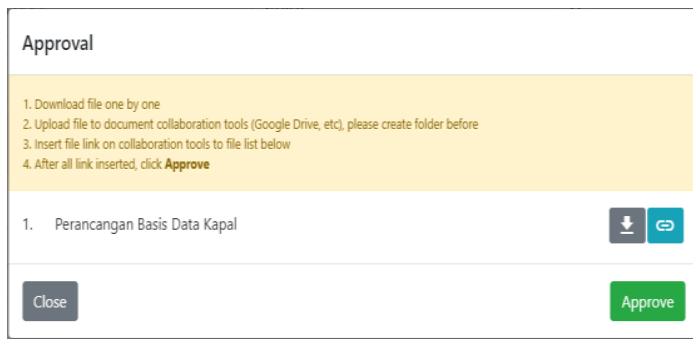

Gambar 11. User Interface untuk menyetujui paper oleh admin.

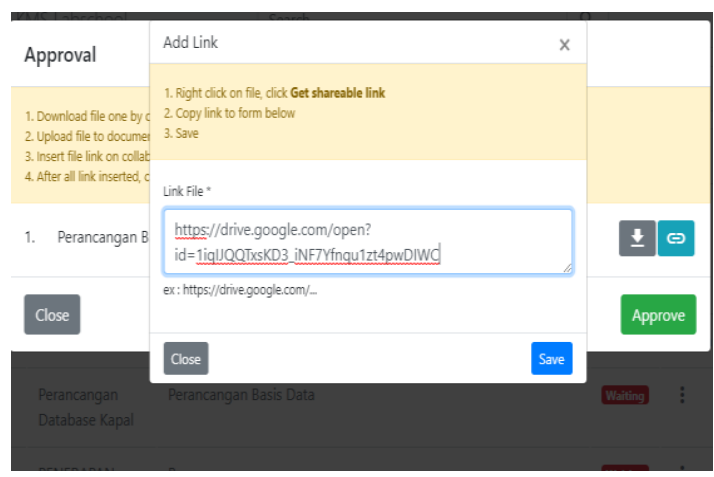

Gambar 12. User Interface untuk insert link file oleh admin

\subsection{Kelebihan Dan Kekurangan \\ Pembelajaran Kolaboratif Berbasis \\ Online \\ Pembelajaran kolaboratif secara online memiliki kelebihan dan}

kekurangan. Kelebihan dari pembelajaran kolaboratif secara online diantaranya adalah

a. Dengan adanya MOOCs setiap orang dapat mengakses secara bebas pengajar yang berkualitas, materi pembelajaran dan latihan yang interaktif (Sonwalkar et al., 2013).

b. Teknologi internet berdampak pada aplikasi pembelajaran kolaboratif dapat diakses kapan saja dan di mana saja selama terhubung dengan jaringan internet.

c. Teknologi pembelajaran kolaboratif online dapat dimanfaatkan bagi pengajar untuk mendukung metode pembelajaran flipped classroom.

Kekurangan dari pembelajaran kolaboratif online diantaranya dilihat dari

a. Biaya teknologi terutama untuk koneksi ke jaringan internet.

b. Pengerjaan tugas atau kuis pada aplikasi pembelajaran online belum dapat menentukan apakah partisipan sendiri yang mengerjakan atau bukan.

c. Pembelajaran kolaboratif berbasis online memerlukan kontrol kualitas proses pembelajaran yang lebih tinggi (Weaver et al., 2008).

\section{SIMPULAN DAN SARAN}

Kesimpulan dari penelitian ini adalah teknologi Pembelajaran MOOCs Aptikom, google classroom dan asmape dapat digunakan untuk mendukung proses pembelajaran kolaboratif secara online. Salah satu kelebihan dari teknologi pembelajaran kolaboratif berbasis online adalah dapat mendukung di dalam metode pembelajaran flipped classroom. 
Sedangkan salah satu kelemahannya adalah dalam pengerjaan tugas atau kuis dimana belum bisa menentukan apakah partisipan sendiri yang mengerjakan ataukah orang lain.

Aplikasi Sistem Manajemen Pengetahuan (http://asmape.com) merupakan salah satu aplikasi LMS yang diintegrasikan dengan google drive sehingga dapat dimanfaatkan untuk menulis paper secara bersama-sama dengan teman kelompoknya.

Sedangkan untuk saran, penelitian lanjutan dapat meneliti mengenai manakah dari ketiga aplikasi kolaboratif pembelajaran online yaitu MOOCs, Google Classroom dan Asmape yang dapat lebih mengoptimalkan higher-order thinking.

\section{UCAPAN TERIMA KASIH}

Ucapan terima kasih disampaikan kepada Kementerian Riset, Teknologi dan Pendidikan Tinggi atas dana hibahnya sehingga aplikasi sistem manajemen pengetahuan dapat terwujud dan dimanfaatkan untuk mendukung proses pembelajaran terutama di dalam pembelajaran kolaboratif berbasis online.

\section{DAFTAR PUSTAKA}

Chunyan, L., Haitao, C., \& Guolin, L. (2014). The Effect of Web 2.0 on Learning Management System. International Journal of Multimedia and Ubiquitous Engineering, 9(10), 67-78.

Iftakhar Shampa. (2016). Google classroom: What works and how? Journal of Education and Social Sciences, 3, 12-18.

Laal, M. (2013). Positive Interdependence in Collaborative Learning. Procedia Social and Behavioral Sciences, 93, 1433-1437.

https://doi.org/10.1016/j.sbspro.2013. 10.058

Manathunga, K., \& Hernández-Leo, D. (2015). Has research on collaborative learning technologies addressed massiveness? A literature review. Educational Technology and Society, 18(4), 357-370.

Moocs Aptikom Course https://mooc.aptikom.or.id/course/index. php?categoryid $=5$ diakses tanggal 18 Agustus 2020

Nurakun Kyzy, Z., Ismailova, R., \& Dündar, H. (2018). Learning management system implementation: a case study in the Kyrgyz Republic. Interactive Learning Environments, 26(8), 1010-1022. https://doi.org/10.1080/10494820.201 8.1427115

Robinson, H. A., Kilgore, W., \& Warren, S. J. (2017). Care, communication, learner support: Designing meaningful online collaborative learning. Online Learning Journal, 21(4), $29-51$. https://doi.org/10.24059/olj.v21i4.124 0

Ryu, H., \& Parsons, D. (2012). Risky business or sharing the load? - Social flow in collaborative mobile learning. Computers and Education, 58(2), 707-720.

https://doi.org/10.1016/j.compedu.20 11.09.019

Setyowati, L. (2015). Online Courses ( MOOCs ) kepada Pustakawan. Media Pustakawan, 22(4), 6-18.

Sonwalkar, M. N., Wilson, P. J., Ng, A., \& Sloep, P. (2013). State-of-the-Field Discussion. MOOCs FORUM, I(P), 6-9.

https://doi.org/10.1089/mooc.2013.00 06

Weaver, D., Spratt, C., \& Nair, C. S. (2008). Academic and student use of 
a learning management system: Implications for quality. Australasian Journal of Educational Technology, 24(1), 30-41. https://doi.org/10.14742/ajet.1228

Yuan, B. L., Powell, S., Yuan, L., Powell, S., \& Cetis, J. (2013). MOOCs and
Open Education: Implications for Higher Education A w hite p aper. 